\title{
A Model of Supervisory System for Ubiquitous Education
}

\author{
http://dx.doi.org/10.3991/ijes.v2i1.3678
}

A.P. Cândido, Instituto Federal de Santa Catarina, Florianópolis, Brasil

A. Heis, Instituto Federal de Santa Catarina, Florianópolis, Brasil

U. C. Correa, Instituto Federal de Santa Catarina, Florianópolis, Brasil

C. T. Vianna, Instituto Federal de Santa Catarina, Gaspar, Brasil

M. R. Kodama, Instituto Federal de Santa Catarina, Florianópolis, Brasil

Abstract - The education supported by e-learning technology has been gaining ground and establishing a new paradigm in this important area of human activity. The technologies available for use in E-learning has advanced in versatility, availability, service area, functionality and affordability. With the availability of peripherals, with the increase on processors, with impressive miniaturization of components and equipment, availability of solutions, both software and hardware, gained special dimensions.

Index Terms —ontology, ubiquitous education, e-learning

\section{Um modelo de sistema supervisor para a educação ubíqua}

\author{
A. P. Cândido ${ }^{1}$, A. Heis ${ }^{1}$, U. C. Corrêa ${ }^{1}$, C. T. Vianna ${ }^{2}$, M. R. Kodama ${ }^{1}$ \\ ${ }^{1}$ IFSC - Instituto Federal de Santa Catarina, Florianópolis, Brasil \\ ${ }^{2}$ IFSC - Instituto Federal de Santa Catarina, Gaspar, Brasil
}

\begin{abstract}
Resumo-A educação suportada por tecnologia E-learning, vem ganhando espaço e estabelecendo um novo paradigma nesta importante área da atividade humana. As tecnologias disponíveis para a utilização em E-learning têm avançado em versatilidade, disponibilidade, área de atendimento, funcionalidade e acessibilidade. Com a disponibilidade de periféricos, com o aumento de processamento dos processadores, com a impressionante miniaturização de componentes e de equipamentos, a disponibilidade de soluções, tanto de software como de hardware, ganhou dimensões especiais.
\end{abstract}

Palavras-chave—ontologia, educação ubíqua, e-learning

\section{INTRODUÇÃO}

Há pouco tempo atrás, o conceito de E-learning já impressionava com a possibilidade de promover aprendizado à pessoas geograficamente distantes do ambiente físico no qual se encontrava o professor ou o instrutor. Os modelos pedagógicos se aperfeiçoaram, as pessoas que participam dos projetos de ensino e aprendizagem, equipe técnica, de apoio, docentes e discentes também assimilou o modelo e se aperfeiçoaram. Um ponto deste cenário que poderia sofrer algum avanço significativo está na ação pedagógica inerente a cada etapa do processo de ensino e de aprendizado. Este ponto poderá ser mais bem assistido considerando a facilidade e disponibilidade da tecnologia existente.

Para maior esclarecimento, considere a rotina de um grupo de pessoas envolvida no processo de ensino e aprendizagem por E-learning. Todos distantes uns dos outros, com pouca referência da rotina de cada integrante do projeto, sem contato visual direto, sem poder interagir fisicamente. Ao que pese o esforço e estratégias para que haja estimulo e suporte para vencer as vicissitudes do trajeto inerente ao projeto, a evasão e o insucesso em determinados momentos é inegável.

Os projetos de E-learning buscam contemplar momentos que promovam entusiasmo por meio de interações síncronas e assíncronas, aperfeiçoando a linguagem e abordagem dos temas, desenvolvendo atividades estimulantes etc. $\mathrm{O}$ fato é que o desafio de manter o aluno no projeto, para a realidade do E-learning é bem maior que no ensino presencial. No presencial o contato, a intensidade das interações são mais presentes, de certa forma isso influi favoravelmente para diminuir o índice de evasão bem para diminuir a sensação de que não se está sozinho na caminhada.

São necessários muitos fatores para que um projeto de ensino e aprendizagem tenha sucesso. O principal deles é a presença da ação docente. Neste sentido o conceito de Educação Ubíqua pode representar um grande avanço para o sucesso da pratica do ensinar e aprender em Elearning.

Os recursos computacionais estão aí para serem utilizados. O desafio é construir o modelo para a aplicação do conceito de educação ubíqua.

\section{A COMPUTAÇÃO UBÍQUA}

Como já expressado, a ubiquidade é uma característica de quem está em todas as partes, em todos os lugares. Considerando este preceito, a computação Ubíqua pressupões a presença da computabilidade em qualquer parte, em todos os lugares. Se considerarmos o avanço tecnoló- 
gico e a realidade deste avanço na presença de computadores no nosso dia-a-dia, vamos perceber que o celular, o relógio a caneta, o automóvel, alguns utensílios nossas maletas, aparelhos de ares condicionados, sistemas de segurança etc... fazem com que efetivamente haja computabilidade em todos os lugares por onde andamos.

A consequência dessa realidade é a possibilidade efetiva de contar com computação a todo momento em qualquer lugar. Considerando isso, pode-se afirmar que há recursos computacionais para fazer muitas coisas em qualquer lugar por onde estivermos. O processador que controla o funcionamento de um ar condicionado poderá suportar algumas rotinas que, em conjunto com o celular do usuário do ambiente poderão processar informações. Este procedimento poderá ser transferido para outros aparelhos de ares condicionados em outros ambientes frequentados pelo dono do celular e assim o mesmo comportamento observado em um ambiente, pode ser reproduzido em outro, bastando para isso a padronização de comunicação entre os equipamentos. Considerando isso, pode-se afirmar que a computação Ubíqua está ai apresentada em linhas gerais.

$\mathrm{O}$ que se pode fazer ou de que forma aproveitar uma realidade como a acima descrita. Muita solução advém da realidade apresentada. Com esta realidade é possível supervisionar equipamentos e pessoas, construir condições de ambiência em salas de escritórios, moradias, salas de aula, ambiente de palestras e outros. Avançando mais nas aplicações e efeitos da realidade tecnológica em foco, é possível identificar uma pessoa que se esteja procurando, saber a proximidade de uma pessoal de nosso interesse, levar e colher informações diversas, supervisionar situações de risco com saúde, eventos climáticos e outros.

O modelo da computação ubíqua ainda está nos primórdios. A maior limitação não está na tecnologia e sim na capacidade de propor e desenvolver solução para ela.

Dentro da perspectiva de análise, a pergunta a ser considerada por este artigo é o grau de contribuição de a computação ubíqua poderá oferecer a E-learning. E como ajustar as tecnologias para oferecer esta contribuição.

\section{EDUCAÇÃO UBÍQUA}

$\mathrm{O}$ conceito de educação ubíqua por consequência do que se está apresentando herda da computação ubíqua seu significado maior. É uma educação presente em todos os lugares a todos os momentos.

Considerando os recursos computacionais existentes pode-se concluir que ela já exista e, efetivamente existe. Um aspecto a ser mais bem considerado e que o artigo em questão poderá representar uma contribuição, é o quanto a educação Ubíqua existe e de que forma existe. A forma na qual a educação Ubíqua se apresenta para a realidade atual é fundamental para determinar o quanto esta modalidade na educação está presente nos ambientes de E-learning.

Para melhor explorar este conceito se o modelo educacional contempla recursos de computação Ubíqua em situações a miúde, ou seja, nas mais diversas formas, meios e conteúdos, a educação Ubíqua é mais presente. Se isso não ocorre, por conseguinte, ela é menos presente.

De que forma arquitetar um ambiente de E-learning para que a educação Ubíqua se faça evidente?

Para a resposta a esta pergunta alguns fatores necessitam ser caracterizados. a) Ambiente Virtual de Ensino e de Aprendizagem. É um ambiente computacional, suportado por software, Hardware e peopleware que, segundo um modelo metodológico implementam recursos e objetos de aprendizagem.

b) Metodologia para o AVEA - está consistida por técnicas, modelos de representação e estratégicas que dão uniformidade de ação e suporte teórico para o desenvolvimento de um modelo de ensino na modalidade E-learning.

c) Eventos de ensino e de aprendizagem - São episódios, momentos por meio do a comunidade que participa do projeto E-learning interage. Neste sentido pode-se ter interação entre vários agentes da comunidade a saber: aluno, professor, tutor, coordenador, equipe técnica, equipe pedagógica, corpo diretivo etc.

\section{UM MODELO PARA IMPLANTAÇÃO DA EDUCAÇÃO UBÍQUA}

A aprendizagem ubíqua, para que se efetive de acordo com seus conceitos e características primordiais, possui o foco da interação com o aluno de forma natural. Busca-se criar um ambiente que seja o mais próximo possível da realidade e utilizar-se dos recursos da tecnologia como vantagem para a explanação de conhecimentos.

O desafio é a comunicação entre usuário e máquina, no caso, entre os envolvidos no processo do E-Learning e os diversos dispositivos que podem ser usados por estes para acessar o sistema. No geral, as limitações da associação de ideias dentro de um hardware são grandes se comparados ao funcionamento do cérebro humano, isso faz com que a maioria dos sistemas computacionais estejam restritos a repassar informações e deixar que o usuário relacione, analise e entenda o que está sendo transmitido. A educação ubíqua remete a necessidade de um sistema de conhecimento, ao próprio computador raciocinando e respondendo ao estudante suas dúvidas ou pesquisas, de forma clara e concisa. Este modelo de funcionamento está interligado diretamente com o funcionamento de uma ontologia.

Uma ontologia é a explanação de conceitos e as relações entre eles dentro de um domínio de conhecimento, num formato taxonômico, de forma clara buscando interpretação única. Considerando o acima exposto, pode-se utilizar e o conceito de que a ontologia é uma especificação explícita e forma de uma conceitualização compartilhada (Studer et al 98).

Basicamente, as ontologias podem ser classificadas nas seguintes categorias:

- Ontologias genéricas: expõe conceitos abrangentes, universais, independentes de um domínio de conhecimento particular;

- Ontologias de domínio: expressam conceitos de determinada área;

- Ontologias de tarefas: descrevem conceitos relacionados a resolução de problemas, independente do domínio em que ocorram;

- Ontologias de aplicação: descrevem conceitos que dependem do domínio e da tarefa em particular; 
- Ontologias de representação: descrevem as conceituações que fundamentam os formalismos de representação de um domínio do conhecimento;

A ideia é que os tipos de ontologias sejam utilizados de acordo com os momentos de aprendizagem, de tal maneira que para cada necessidade se possa ter um comportamento suportado por um modelo de ontologia.

\section{DISCUSSÃO}

A aplicação dos vários tipos de ontologias permitem ou possibilitam atender as várias necessidade de um processo de E-learning de tal forma que a educação se faça presente em muitos aconteceres da vida dos integrantes de um processo de ensino e aprendizagem mediado por computador.

\section{REFERÊNCIAS}

[1] MORAIS, E. A. M., AMBRÓSIO, A. P. L. Ontologias: conceitos, usos, tipos, metodologias, ferramentas e linguagens, 2007.

[2] STUDER, R.; BENJAMINS, R.; FENSEL, D. Knowledge Engineering: Principles and methods, 1997;
[3] BARBOSA, D. N. F., SARMENTO, D. F., BARBOSA, J. L. V., GEYER, C. F. R. Em direção a Educação Ubíqua: aprender sempre, em qualquer lugar, com qualquer dispositivo, 2008.

\section{AUTORES}

A. P. Cândido, professor do Instituto Federal de Santa Catarina (IFSC), Av. Mauro Ramos, 950, Centro, Florianópolis/SC - apec@ifsc.edu.br

A. Heis, professor do Instituto Federal de Santa Catarina (IFSC), Av. Mauro Ramos, 950, Centro, Florianópolis/SC - adriano.heis@ifsc.edu.br

C. T. Vianna, professor do Instituto Federal de Santa Catarina (IFSC), campus Gaspar - tabajara@ifsc.edu.br

U. C. Corrêa, professor do Instituto Federal de Santa Catarina, Av. Mauro Ramos, 950, Centro, Florianópolis/SC - underlea.correa@ifsc.edu.br

M. R. Kodama, estudante do Instituto Federal de Santa Catarina (IFSC), Av. Mauro Ramos, 950, Centro, Florianópolis/SC - rkmarinark@gmail.com

Submitted 19 March 2014. Published as re-submitted by the authors 05 April 2014. 